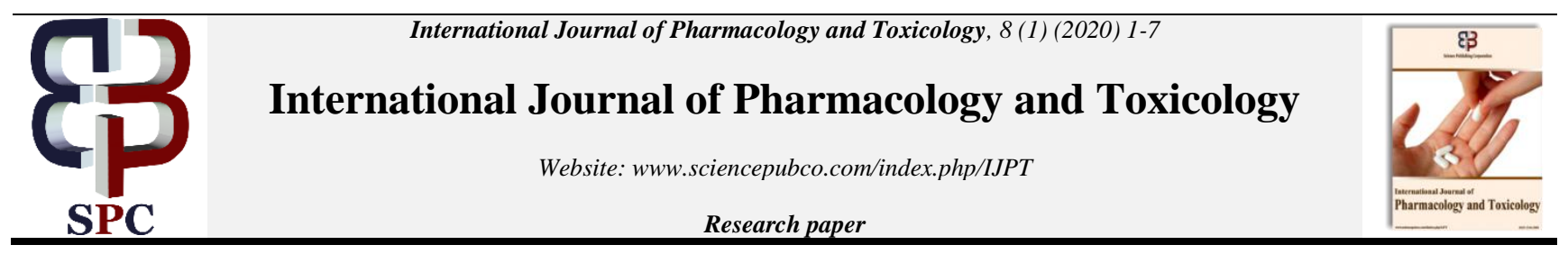

\title{
Dose and time-dependent acute and subchronic oral toxicity study of propoxazepam in mice and rats
}

\author{
Nikolay Yakovlevich Golovenko ${ }^{1 *}$, Valentina Nikolayevna Kovalenko ${ }^{2}$, Vitalii Borisovich \\ Larionov ${ }^{1}$, Anatoliy Semenovich Reder ${ }^{1}$ \\ ${ }^{1}$ A.V. Bogatsky Physico-Chemical, Institute of the National Academy of Sciences of Ukraine, \\ 86 Lustdorfskaya doroga, 65080 Odessa, Ukraine \\ ${ }^{2}$ Institute of Pharmacology and Toxicology of the National Academy of Medical Sciences of Ukraine. 03380, \\ Kiev, st. Anton Saddik, 14
}

\begin{abstract}
Propoxazepam, 7-bromo-5 - (o-chlorophenyl)-3-propoxy - 1,2-dihydro - 3H-1,4-benzodiazepin-2-one, in the models of nociceptive and neuropathic pain showed significant analgesic activity. In order to explore clinical potential of propoxazepam for long term human consumption, toxicology testing in laboratory animals using well-accepted international guidelines is required. Acute toxicity tests were conducted by the oral administration of $2500 ; 3500 ; 4000 ; 4500$ and $5000 \mathrm{mg} / \mathrm{kg}$ body weight to male and female mice and rats for a period of 3,7 and 14 day. In subacute study, male rats were administered with various doses of propoxazepam $(0.9,4.5$, and $9.0 \mathrm{mg} / \mathrm{kg})$ to evaluate its toxicity for a period of 90 days. The effect of propoxazepam on body weight gain and organ weights, food and water consumptions were analyzed. From the present study, it can be concluded that the acute (3,7 and 14 days) and subchronic (90 days) oral administrations of propoxazepam did not produce any clinical signs of toxicity or mortality of the male and female mice and rats. These results revealed that the $\mathrm{LD}_{50}$ of propoxazepam is greater than $5000 \mathrm{mg} / \mathrm{kg}$ and it therefore, belongs to the category $\mathrm{V}$ of relatively non-toxic substances according to the GHS. In the acute toxicity study, neither mortality no significant change in the body weight and the relative organ weights were recorded in all treated mice and rats. Present data set revealed that there wasn't a strong correlation between body weight with food and water consumptions. The result indicates that the oral administration of propoxazepam did not produce any significant toxic effect in mice and rats and the substance can be safely used for therapeutic use in pharmaceutical formulations.
\end{abstract}

Keywords: Propoxazepam; Acute; subchronic Oral Toxicity; Body and Organ Weights; Food and Water Consumption.

\section{Introduction}

Propoxazepam, 7-bromo-5-(o-chlorophenyl)-3-propoxy-1,2-dihydro-3H-1,4-benzodiazepin-2-one, in the models of nociceptive and neuropathic pain showed significant analgesic activity ( Golovenko, 2018). Similar to gabapentin and pregabalin, which are well-known antiepileptic drugs used in general medical practice for the treatment of neuropathic pain, propoxazepam also has an anticonvulsant effect (Golovenko et al., 2017, Golovenko et al., 2018), which explains the analgesic component of the pharmacological spectrum. Both oral and intraperitoneal administrations are similar in activity, although intraperitoneal administration is preferred. It has proven in in vivo studies to be the potent drug in its class against acute and chronic pain.

Our data suggest that the mechanism of propoxazepam anticonvulsant properties includes GABAergic and glycinergic systems (Golovenko et al., 2017, Golovenko et al., 2018). Antibradykinin and antileukotriene action, dopaminergic system, NMDA, and alpha-1 adrenergic receptors, except the antiprostaglandin component, are involved in the mechanisms of propoxazepam analgesic effect (Voloshchuk et al., 2018).

In order to explore clinical potential of propoxazepam for long term human administration, toxicology testing in laboratory animals using well-accepted international guidelines is required. Therefore, the present study aimed to evaluate the possible toxicological profiles of propoxazepam single dose (acute oral toxicity) and repeated dose (90-days, subchronic) toxicity, by assessing its physical (body weight gain and organ weights) and physiological (food and water consumption) parameters in rats and mice. 


\section{Materials and methods}

\subsection{Drugs and chemicals}

Propoxazepam was synthesized according to the method described in (Andronati et. al., 2010). The structure of the substance was determined and approved by a complex of physicochemical methods (IR and mass spectroscopy, as well as X-ray diffraction analysis). Chemical purity was confirmed by elemental analysis $(99 \%)$.

\section{Animals}

Rats and mice were obtained from the animal house of the Institute Pharmacology and Toxicology NAMS of Ukraine. Male and nonpregnant female rats (200-220 g) and male and female (non-pregnant) mice (25-30 g)), were housed in a temperature and light-controlled room $\left(24.0 \pm 2{ }^{\circ} \mathrm{C} ; 12 \mathrm{~h}\right.$ light/dark cycle). Before starting the experiments, animals were randomly selected, marked on the tail to permit individual identification, and kept in their cages for 5 days to allow for acclimatization to the laboratory conditions. The experiments were carried out according to the recommendations of the Committee for Research and Ethical Issues of the IASP (1983) and were approved by the regional ethical committee for animal research. All manipulations were made to minimize animal suffering and to reduce the number of animals used.

The test compounds were administered in suspension stabilized with hydroxypropyl methylcellulose (HPMC), and the control animals received corresponding amount of vehicle (HPMC).

\section{Toxicological evaluation}

\subsection{Acute oral toxicity testing}

The acute oral toxicity test was performed using methods described in OECD Test Guidelines 425 (OECD Guideline, 2008). Male and female rats and mice (6 animals per group) were orally treated with propoxazepam at doses of 2500; 3500; $4000 ; 4500$ and $5000 \mathrm{mg} / \mathrm{kg}$. The oral route of administration is the most useful and normally used one while doing toxicity study. The absorption may be slow; however, this methodology expenses less and is painless to the animals. The test compounds were suspended in hydroxypropyl methylcellulose (HPMC), and the control animals received corresponding amount of vehicle (HPMC). Each group of rats was placed in a test cage for a 45-min adaptation period before oral administration of propoxazepam using an gavage cannula. The body weight of each animal was determined on the first day of experiment and 3; 7 and 14 days after experiment beginning, and the body weight gain was calculated using the mean difference between weight per these periods. Physiological parameters (food consumption) were determined weekly. Animals were weighed on day 0 , and then on days 3,7 and 14. At the end of the study, all surviving animals were sacrificed and some internal organs such as lungs, liver, kidney, spleen, brain and heart were removed and weighed. The $\mathrm{LD}_{50}$ was evaluated and propoxazepam classified according to the Globally Harmonized System (GHS) for the classification of chemicals (OECD, 1998).

\subsection{Subchronic (90-day repeated dose) oral toxicity tests}

The subchronic 90-day oral toxicity study was evaluated following the recommendations by OECD (1998) (OECD, 1998). Spargue Dawley male rats were randomly distributed to four groups of eight animals each. Propoxazepam prepared in HPMC orally administered daily for 90 days in single doses of $0,9 \mathrm{mg} / \mathrm{kg}$ (group 1), $4,5 \mathrm{mg} / \mathrm{kg}$ (group 2), or $9,0 \mathrm{mg} / \mathrm{kg}$ (group 3). The choice of dosages for the 90 -day toxicity study were based on previous pharmacological testing, during which the efficacy of propoxazepam was demonstrated using oral administration of $0,9 \mathrm{mg} / \mathrm{kg}$ [Golovenko et al. 2017, 2018, OECD Guidelines, 2017] and its pharmacokinetic (Larionov, 2018). The control rats (group 4) received only vehicle (HPMC). During the study, all animals were monitored for clinical, behavioral, and functional symptoms.

\subsection{Measurement of body and organ weights changes}

At termination of the studies, the animals were observed daily for clinical toxicity signs and mortality. The animals were weighed prior to dosing, after every 7 days, and before sacrifice on the last day. Weight of each rat was recorded separately. After administration of propoxazepam, the animals were anaesthetized in airtight dissection jar containing cotton soaked in chloroform. Each anaesthetized animal was dissected on a vertical mid-line and the organs (lungs, liver, kidney, spleen, brain and heart) were excised and weighed after washing in normal saline. The weight of all rats were taken using calibrated weighing balance. The weight of organs showing gross abnormality was not included in the study data. For each animal, the percent weight change was calculated: difference between interval and initial body weight $\div$ initial body weight $) \times 100$. The mean of values for each group was then calculated to give $\%$ weight change \pm SD. The weight of each organ relative to $100 \mathrm{~g}$ of the body weight of the rats from which the organs were excised was calculated as: [organ weight $(\mathrm{g}) \div$ bodyweight of $\operatorname{rat}(\mathrm{g})] \times 100$

\subsection{Effect of the substance on the weight, feed and water intake of the rats}

Feed and water intakes were measured everyday at the same aytime during the experimental periods while the body weight of the animals were measured at zero day and every twelve weeks for the period of 90 days. 


\section{Statistical analysis}

The data are represented as mean \pm SEM. Statistical significance was carried out employing one way analysis of variance (ANOVA) followed by Tukey post hoc test, where $\mathrm{p}<0.05$ was statistically considered significant.

\section{Results}

\subsection{Acute toxicity study}

\subsubsection{Determination clinical signs and $\mathrm{LD}_{50}$ test of propoxazepam}

The results showed that after propoxazepam administration at single oral doses of 2500; 3500; 4000; 4500 and $5000 \mathrm{mg} / \mathrm{kg}$, mice and rats of both sexes had no death recorded during the entire period of observation. Only after dosage of $5000 \mathrm{mg} / \mathrm{kg}$ the animals gradually became sedated in crouched or prone position in association with frequent eye-closure and decrease in right behavior to tactile stimulation, these sedative symptoms persisting for about 4 hours. There were no abnormal observations in body weight of rats. No abnormalities or pathological changes were observed during the necropsy. Under the experimental conditions, the results indicated that the median lethal dose (LD50) of propoxazepam is greater than $5000 \mathrm{mg} / \mathrm{kg}$ of body weight. Thus, propoxazepam may be assigned to category 5 as the lowest class of toxicity according to the GHS.

\subsubsection{Effects of propoxazepam on weight gain of mice and rats}

For a detailed study of body mass dynamics and the state of the internal organs of experimental animals, a doses of $2500-5000 \mathrm{mg} / \mathrm{kg}$ orally were chosen that did not cause death of mice. Animals in this groups were monitored for body weight prior to propoxazepam administration, as well as on the $3^{\text {th }}, 7^{\text {th }}$ and $14^{\text {th }}$ day of the experiment. Table 1 shows the mean body weights of the female and male mice. There were no differences in body weights between the treatment groups female mice and the control group throughout the experimental period. There were no treatment-related changes in body weight in the female rats (table 2$)$. Weight gain of male animals $(\mathrm{p}<0,05)$ treated with doses 2500,4000 , and $5000 \mathrm{mg} / \mathrm{kg}$ was noted at 7 th and 14 th (mice) and at doses 2500 and $5000 \mathrm{mg} / \mathrm{kg}$ ( $\mathrm{p}<0,05$, rats).

Table 1: Effects of Propoxazepam on Body Weight of Mice in Acute Toxicity Studies

\begin{tabular}{|c|c|c|c|c|}
\hline \multirow[b]{2}{*}{ Propoxazepam (mg/kg) } & \multicolumn{3}{|l|}{ Days } & \multirow[b]{2}{*}{14} \\
\hline & $\begin{array}{l}0 \\
\text { Female }\end{array}$ & 3 & 7 & \\
\hline 5000 & $20,33 \pm 0,56$ & $19,33 \pm 0,33$ & $19,83 \pm 0,48$ & $20,00 \pm 0,37$ \\
\hline 4500 & $19,50 \pm 0,51$ & $18,50 \pm 0,77$ & $18,50 \pm 0,66$ & $19,67 \pm 0,77$ \\
\hline 4000 & $20,00 \pm 0,37$ & $19,83 \pm 0,54$ & $20,67 \pm 0,67$ & $22,50 \pm 0,67$ \\
\hline 3500 & $20,50 \pm 0,39$ & $19,17 \pm 0,28$ & $20,50 \pm 0,20$ & $21,50 \pm 0,39$ \\
\hline 2500 & $20,00 \pm 0,33$ & $19,00 \pm 0,53$ & $20,67 \pm 0,30$ & $21,50 \pm 0,39$ \\
\hline \multicolumn{5}{|l|}{ Male } \\
\hline 5000 & $20,00 \pm 0,68$ & $19,83 \pm 0,60$ & $20,33 \pm 0,49$ & $22,33 \pm 0,49 *$ \\
\hline 4500 & $20,17 \pm 0,50$ & $19,67 \pm 0,56$ & $21,17 \pm 0,44$ & $23,17 \pm 0,37 *$ \\
\hline 4000 & $19,83 \pm 0,60$ & $18,67 \pm 0,42$ & $20,33 \pm 0,21 *$ & $22,67 \pm 0,37 *$ \\
\hline 3500 & $20,17 \pm 0,28$ & $19,00 \pm 0,78$ & $20,83 \pm 0,55$ & $21,67 \pm 0,30$ \\
\hline 2500 & $20,33 \pm 0,45$ & $18,33 \pm 0,45^{*}$ & $20,50 \pm 0,46^{*}$ & $21,83 \pm 0,50 *$ \\
\hline
\end{tabular}

Day 0 = first dosing day.

Results are expressed as a mean \pm SEM; $n=6$.

$*$ - $<<0,05$ : values are significantly different from controls at the same days.

Table 2: Effects of Propoxazepam on Body Weight of Rats in Acute Toxicity Study

\begin{tabular}{llll}
\hline & Days & 3 & 7 \\
Propoxazepam $(\mathrm{mg} / \mathrm{kg})$ & 0 & & 14 \\
\hline 5000 & Female & $186,0 \pm 2,5$ & $187,8 \pm 2,5$ \\
4500 & $187,7 \pm 2,7$ & $190,3 \pm 2,3$ & $192,8 \pm 1,7$ \\
4000 & $192,3 \pm 1,9$ & $191,7 \pm 2,5$ & $194,2 \pm 1,1$ \\
3500 & $193,8 \pm 1,7$ & $192,5 \pm 1,1$ & $193,0 \pm 1,8$ \\
2500 & $193,8 \pm 1,9$ & $201,5 \pm 2,95$ & $201,8 \pm 2,7$ \\
Male & $204,2 \pm 3,0$ & & $2,7 \pm 2,9$ \\
5000 & & $198,7 \pm 1,6$ & $196,2 \pm 1,3$ \\
4500 & $196,5 \pm 1,8$ & $199,5 \pm 1,6$ & $201,0 \pm 1,5$ \\
4000 & $197,2 \pm 1,7$ & $202,0 \pm 0,6$ & $204,2 \pm 0,3^{*}$ \\
3500 & $198,5 \pm 2,4$ & $200,3 \pm 1,9$ & $202,7 \pm 1,7$ \\
2500 & $197,2 \pm 1,6$ & $203,5 \pm 0,6$ & $206,2 \pm 0,5^{*}$ \\
\hline
\end{tabular}

Day 0 = first dosing day.

Results are expressed as a mean \pm SEM; $n=6$.

$*-p<0,05$ : values are significantly different from controls at the same days.

Influence of propoxazepam on relative organ weight after 14 days of its administration to mice and rats at doses $2500-5000 \mathrm{mg} / \mathrm{kg}$.

The data of relative organ weights of propoxazepam treated mice and rats during treatment and reversal period in male and female animals is presented in table 3 and table 4 . None of the propoxazepam treated group showed significant difference during treatment or reversal 
period as compared with corresponding control group. No treatment-related gross pathological changes were observed in any organs of the test animals during necropsy

Table 3: Relative Organ Weight (\%) After 14 Days Propoxazepam Administration at Doses 2500-5000 Mg/Kg To Mice

\begin{tabular}{|c|c|c|c|c|c|c|}
\hline Propoxazepam (mg/kg) & $\begin{array}{l}\text { Organs } \\
\text { Female } \\
\text { lungs }\end{array}$ & liver & kidneys & spleen & brain & heart \\
\hline 5000 & $1,04 \pm 0,02$ & $5,86 \pm 0,10$ & $1,20 \pm 0,04$ & $0,95 \pm 0,03$ & $1,21 \pm 0,04$ & $0,48 \pm 0,02$ \\
\hline 4500 & $1,00 \pm 0,01$ & $5,93 \pm 0,22$ & $1,21 \pm 0,03$ & $0,95 \pm 0,02$ & $1,22 \pm 0,03$ & $0,46 \pm 0,10$ \\
\hline 4000 & $0,90 \pm 0,03$ & $5,19 \pm 0,13$ & $1,19 \pm 0,02$ & $0,86 \pm 0,03$ & $1,14 \pm 0,04$ & $0,50 \pm 0,02$ \\
\hline 3500 & $1,01 \pm 0,02$ & $5,53 \pm 0,13$ & $1,21 \pm 0,04$ & $0,92 \pm 0,02$ & $1,21 \pm 0,03$ & $0,49 \pm 0,02$ \\
\hline 2500 & $1,03 \pm 0,04$ & $5,41 \pm 0,11$ & $1,17 \pm 0,04$ & $0,89 \pm 0,01$ & $1,15 \pm 0,02$ & $0,48 \pm 0,02$ \\
\hline Control & $0,98 \pm 0,04$ & $5,28 \pm 0,14$ & $1,19 \pm 0,04$ & $0,88 \pm 0,03$ & $1,14 \pm 0,03$ & $0,48 \pm 0,03$ \\
\hline \multicolumn{7}{|l|}{ Male } \\
\hline 5000 & $0,99 \pm 0,01$ & $5,26 \pm 0,13$ & $1,12 \pm 0,02$ & $0,83 \pm 0,06$ & $1,10 \pm 0,01$ & $0,45 \pm 0,01$ \\
\hline 4500 & $0,96 \pm 0,02$ & $5,08 \pm 006$ & $1,04 \pm 0,04$ & $0,88 \pm 0,05$ & $1,06 \pm 0,03$ & $0,60 \pm 0,18$ \\
\hline 4000 & $0,92 \pm 0,01$ & $5,32 \pm 0,07$ & $1,19 \pm 0,01$ & $0,88 \pm 0,02$ & $1,17 \pm 0,02$ & $0,50 \pm 0,02$ \\
\hline 3500 & $0,98 \pm 0,01$ & $5,39 \pm 0,07$ & $1,18 \pm 0,03$ & $0,91 \pm 0,02$ & $1,18 \pm 0,02$ & $0,48 \pm 0,01$ \\
\hline 2500 & $1,01 \pm 0,03$ & $5,39 \pm 0,12$ & $1,14 \pm 0,04$ & $0,88 \pm 0,02$ & $1,13 \pm 0,03$ & $0,48 \pm 0,01$ \\
\hline Control & $0,97 \pm 0,04$ & $5,28 \pm 0,11$ & $1,15 \pm 0,05$ & $0,90 \pm 0,05$ & $1,16 \pm 0,04$ & $0,50 \pm 0,11$ \\
\hline
\end{tabular}

Table 4: Relative Organ Weight (\%) after 14 Days Propoxazepam Administration at Doses of 2500-5000 Mg/Kg to Rats

\begin{tabular}{|c|c|c|c|c|c|c|}
\hline Propoxazepam (mg/kg) & $\begin{array}{l}\text { Organs } \\
\text { Female } \\
\text { lungs }\end{array}$ & liver & kidneys & spleen & brain & heart \\
\hline 5000 & $1,12 \pm 0,07$ & $5,21 \pm 0,21$ & $0,95 \pm 0,03$ & $0,66 \pm 0,09$ & $0,79 \pm 0,01$ & $0,43 \pm 002$ \\
\hline 4500 & $1,01 \pm 0,04$ & $5,25 \pm 0,08$ & $0,97 \pm 0,01$ & $0,48 \pm 0,04$ & $0,77 \pm 0,01$ & $0,42 \pm 0,01$ \\
\hline 4000 & $0,95 \pm 004$ & $5,03 \pm 0,15$ & $0,99 \pm 0,02$ & $0,49 \pm 0,02$ & $0,77 \pm 0,01$ & $0,43 \pm 0,01$ \\
\hline 3500 & $1,00 \pm 0,02$ & $5,07 \pm 0,06$ & $0,92 \pm 0,04$ & $0,50 \pm 0,02$ & $0,76 \pm 0,01$ & $0,43 \pm 0,01$ \\
\hline 2500 & $0,98 \pm 0,03$ & $5,11 \pm 0,16$ & $0,94 \pm 0,03$ & $0,55 \pm 0,02$ & $0,75 \pm 0,01$ & $0,40 \pm 0,01$ \\
\hline Control & $0,99 \pm 0,3$ & $5,17 \pm 0,20$ & $0,96 \pm 0,01$ & $0,54 \pm 0,09$ & $0,78 \pm 0 / 02$ & $0 / 42 \pm 0,02$ \\
\hline \multicolumn{7}{|l|}{ Male } \\
\hline 5000 & $1,02 \pm 0,05$ & $4,99 \pm 0,18$ & $0,88 \pm 0,03$ & $0,60 \pm 0,07$ & $0,72 \pm 0,01$ & $0,41 \pm 0,02$ \\
\hline 4500 & $0,93 \pm 0,01$ & $5,22 \pm 0,21$ & $0,90 \pm 0,01$ & $0,47 \pm 0,04$ & $0,74 \pm 0,01$ & $0,42 \pm 0,01$ \\
\hline 4000 & $0,92 \pm 0,03$ & $4,99 \pm 0,15$ & $0,95 \pm 0,01$ & $0,48 \pm 0,01$ & $074 \pm 0,01$ & $0,44 \pm 0,01$ \\
\hline 3500 & $0,94 \pm 002$ & $5,02 \pm 0,20$ & $0,92 \pm 0,02$ & $0,51 \pm 0,01$ & $0,75 \pm 0,01$ & $0,42 \pm 0,01$ \\
\hline 2500 & $1,00 \pm 0,03$ & $5,23 \pm 0,16$ & $0,93 \pm 0,02$ & $0,58 \pm 0,05$ & $0,74 \pm 0,01$ & $0,42 \pm 0,01$ \\
\hline Control & $0,97 \pm 0,03$ & $5,20 \pm 0,02$ & $0,94 \pm 0,03$ & $0,52 \pm 0,04$ & $0,73 \pm 0,02$ & $0,43 \pm 0,02$ \\
\hline
\end{tabular}

Effect of propoxazepam on organ's weight, food consumption and water intake in sub-acute oral toxicity tests.

The subchronic oral toxicity study in rats was performed for 90 days and none of the propoxazepam treated animals died or exhibited abnormal clinical signs at any of the tested doses. The variation of the body weight of rats is shown in table 5. During the experiment the body weight variation of rats in all test groups was different compared to that of control. However, a body weight of rats at dose 0,9 mg/kg at 5-14 weeks statistically significantly $(\mathrm{p}<0.05, \mathrm{p}<0,01)$ increased after propoxazepam administration and remained under the normal range during the experiment.

Table 5: Effects of Ropoxazepam on Body Weight of Male Rates in Subchronic Toxicity Study $(M \pm M, N=8)$

\begin{tabular}{|c|c|c|c|c|}
\hline Weeks & Control & $\begin{array}{l}\text { Pronoxazenam. } \mathrm{mg} / \mathrm{kg} \\
0.9\end{array}$ & 4.5 & 9.0 \\
\hline 1 & $19850+377$ & $20238+258$ & $1930+337$ & $20313+470$ \\
\hline 2 & $221.88+3.41$ & $233.88+4.28$ & $219.0+4.63$ & $226.50+5.39$ \\
\hline 3 & $246.50 \pm 4.42$ & $258.88 \pm 5.19$ & $236.38 \pm 4.59$ & $246.0 \pm 6.11$ \\
\hline 4 & $261.25+5.98$ & $271.38+5.23$ & $252.75+6.26$ & $256.63+6.31$ \\
\hline 5 & $268.38 \pm 5.13$ & $296.88 \pm 6.08 * *$ & $269.75 \pm 6.04$ & $279.63 \pm 6.34$ \\
\hline 6 & $284.13+5.24$ & $311.0+7.40 *$ & $280.13+7.55$ & $292.50+5.82$ \\
\hline 7 & $294.38+8.01$ & $328.38+7.76 *$ & $289.75+7.48$ & $303.25+6.31$ \\
\hline 8 & $303.13+8.03$ & $339.5+08.88 *$ & $296.30+8.03$ & $310.88+6.76$ \\
\hline 9 & $313.75+8.29$ & $352.13+8.85 * *$ & $304.63+7.75$ & $315.13+6.98$ \\
\hline 10 & $321 . .38+8.14$ & $358.88+10.22 *$ & $311.13+8.25$ & $317.50+7.63$ \\
\hline 11 & $324.0+9.16$ & $362.13+9.91 *$ & $318.38+8.68$ & $326.63+8.42$ \\
\hline 12 & $331.13+9.67$ & $368.88+10.18 *$ & $325.25+9.22$ & $306.25+8.01$ \\
\hline
\end{tabular}

Food consumption in rats daily treated with $0.9 \mathrm{mg} / \mathrm{kg}$ of propoxazepam showed an increase in food consumption when compared to control with the exception on the following weeks: $1,3,8$ and 9 , their difference was significant $(\mathrm{p}<0.001)$. At increased dose $(4.5 \mathrm{mg} / \mathrm{kg})$ propoxazepam showed a decrease in food consumption compared to control next weeks: $1-3,5$ and $9,10^{\text {th }}(\mathrm{p}<0.001)$. In group 3 , rats administered with $9.0 \mathrm{mg} / \mathrm{kg}$ of propoxazepam showed a increase in weight of food consumed only on 3, 4, 8-10 and $12^{\text {th }}$ weeks (table 6).

Table 6: Food Consumption, measured on the $1^{\text {st }}-12^{\text {th }}$ Weeks of Propoxazepam Administration to Male Rats $(N=8, M e a n ~ \pm S E M)$

\begin{tabular}{|c|c|c|c|c|}
\hline Week & Control & $\begin{array}{l}\text { Dose, } \mathrm{mg} / \mathrm{kg} \\
0,9\end{array}$ & 4,5 & 9,0 \\
\hline 1 & $21,50 \pm 0,97$ & $22,63 \pm 0,88$ & $17,63 \pm 1,33^{*}$ & $20,75 \pm 1,91$ \\
\hline 2 & $19,50 \pm 0,98$ & $23,63 \pm 0,64 * *$ & $16,13 \pm 0,76^{*}$ & $20,50 \pm 2,20$ \\
\hline
\end{tabular}




\begin{tabular}{llll}
\hline 3 & $23,0 \pm 0,83$ & $23,38 \pm 0,50$ & $18,25 \pm 0,66^{* *}$ \\
4 & $19,75 \pm 0,42$ & $25,0 \pm 0,43 * *$ & $17,75 \pm 0,88$ \\
5 & $21,0 \pm 0,40$ & $18,88 \pm 0,28^{* *}$ & $17,75 \pm 0,79 * *$ \\
6 & $16,13 \pm 0,45$ & $21,75 \pm 0,46^{* *}$ & $18,50 \pm 0,90$ \\
7 & $17,13 \pm 0,72$ & $26,63 \pm 1,61^{* *}$ & $18,50 \pm 0,71$ \\
8 & $19,38 \pm 0,25$ & $18,25 \pm 0,46$ & $18,75 \pm 0,37 * 0,67$ \\
9 & $15,13 \pm 0,41$ & $14,88 \pm 0,57$ & $18,88 \pm 0,78^{* *}$ \\
10 & $12,88 \pm 0,37$ & $21,0 \pm 0,61^{* *}$ & $18,63 \pm 0,61^{* *}$ \\
11 & $17,88 \pm 0,57$ & $21,75 \pm 0,63^{* *}$ & $18,75 \pm 0,55$ \\
12 & $18,38 \pm 0,61$ & $22,13 \pm 0,67 * *$ & $13,69 \pm 0,46$ \\
\hline
\end{tabular}

$*_{-} \mathrm{p}<0,05, * *_{-} \mathrm{p}<0,01$ : values are significantly different from control at the same days.

Administration of propoxazepam at doses of $0.9,4.5$ and $9.0 \mathrm{mg} / \mathrm{kg}$ to rats resulted in a significant $(\mathrm{p}<0.05$, $\mathrm{p}<0.001)$ increase in water intake for $0.9 \mathrm{mg} / \mathrm{kg}(5,6,10-12$ weeks) for $4.5 \mathrm{mg} / \mathrm{kg}(1-5,7$ and 8 weeks) and for $9.0 \mathrm{mg} / \mathrm{kg}(4,6-8,10-12$ weeks) compared to control (Table 7). The control rats exhibited also non normal drinking behavior in 6,7 and 9,10 weeks.

Table 7: Water Intake, measured on the $1^{\text {st }}-14^{\text {th }}$ Weeks of Propoxazepam Administration to Male Rats $(\mathrm{N}=8, \mathrm{Mean} \pm \mathrm{SEM})$

\begin{tabular}{llll}
\multicolumn{5}{c}{ Table 7: Water Intake, measured on the $1^{\text {st }}-14^{\text {th }}$ Weeks of Propoxazepam Administration to Male Rats $(\mathrm{N}=8$, Mean \pm SEM) } \\
\hline Weeks & Control & 0,9 & 4,5 \\
\hline 1 & $31,13 \pm 1,15$ & $32,38 \pm 1,32$ & $25,13 \pm 1,64^{*}$ \\
2 & $32,13 \pm 1,27$ & $34,0 \pm 1,06$ & $20,88 \pm 0,96^{* *}$ \\
3 & $31,63 \pm 0,77$ & $35,13 \pm 1,55$ & $25,25 \pm 1,30^{*}$ \\
4 & $31,75 \pm 0,66$ & $34,50 \pm 1,19$ & $29,88 \pm 2,80$ \\
5 & $32,38 \pm 0,58$ & $28,0 \pm 0,90^{* *}$ & $29,38 \pm 0,58^{*}$ \\
6 & $26,63 \pm 0,68$ & $32,88 \pm 0,94^{* *}$ & $23,50 \pm 1,33^{* *}$ \\
7 & $31,50 \pm 0,50$ & $38,13 \pm 1,92^{*}$ & $25,0 \pm 1,37$ \\
8 & $32,50 \pm 0,71$ & $29,50 \pm 1,32$ & $26,881,43 *$ \\
9 & $26,50 \pm 0,98$ & $30,0 \pm 1,37$ & $25,63 \pm 1,47^{* *}$ \\
10 & $24,75 \pm 1,60$ & $33,63 \pm 1,38^{* *}$ & $26,75 \pm 1,93$ \\
11 & $29,25 \pm 1,09$ & $36,13 \pm 1,05^{* *}$ & $26 \pm 1,98^{* *}$ \\
12 & $31,63 \pm 1,01$ & $35,88 \pm 1,07^{*}$ & $28,75 \pm 1,48$ \\
\hline
\end{tabular}

$*_{-} \mathrm{p}<0,05, * *_{-} \mathrm{p}<0,01$ : values are significantly different from control at the same days.

\section{Discussion}

Acute toxicity information is of limited clinical application because cumulative toxic effects do occur even at very low doses. Consequently, multiple dose studies are typically useful in evaluating the safety profile of innovative medicines. There are many different types of toxicity studies carried out for evaluation of toxic effects of therapeutic agents or potential toxicants that could pose threat to the lives of humans and animals. The traditional methods of determining toxic effects of chemicals and drugs include acute toxicity study (Saganuwan 2017) which is carried out to determine the short time toxicity effect of a toxicant ( $1 \mathrm{~s}$ to 2 weeks), whereas subacute toxicity study is carried out to know the relative long term effect of a toxicant (4 weeks -6 months). The present study demonstrated the preclinical safety of propoxazepam during acute and subchronic (90-days repeated dose) administration in mice and rats. The use of two animal species is justified by the possible difference in results between species, although both are rodents.

Under the experimental conditions, the results indicated that the median lethal dose $\left(\mathrm{LD}_{50}\right)$ of propoxazepam is higher than $5000 \mathrm{mg} / \mathrm{kg}$. Thus, propoxazepam may be assigned to category $\mathrm{V}$ as the lowest class of toxicity according to the GHS. It should be noted that the toxicity of known 1,4-benzodiazepines drugs is significantly higher. Thus, diazepam is $1240 \mathrm{mg} / \mathrm{kg}$ (rats), $720 \mathrm{mg} / \mathrm{kg}$ (mice); lorazepam is 3178 $\mathrm{mg} / \mathrm{kg}$ (rats); nitrazepam is $980 \mathrm{mg} / \mathrm{kg}$ (rats); flunitrazepan is $415 \mathrm{mg} / \mathrm{kg}$ (rats); temazepam is $833 \mathrm{mg} / \mathrm{kg}$ (rats); alprazolam is $331-2171$ $\mathrm{mg} / \mathrm{kg}$ (rats); flumazenil is 100-300 mg/kg (mice), $100-1000 \mathrm{mg} / \mathrm{kg}$ (rats) (Koella 1985, Robert 2004).

A number of drugs are capable of changing bodyweight as an adverse effect of their therapeutic action. Subchronic oral treatment with 0,9$9,0 \mathrm{mg} / \mathrm{kg} /$ day of propoxazepam over the period of 90 days was associated with significant decrease in the weight gain pattern of propoxazepam-treated rats in a non dose dependent manner. A body weight of rats at dose $0,9 \mathrm{mg} / \mathrm{kg}$ at $5-14$ weeks statistically significantly $(p<0.05, p<0,01)$ increased after administration of propoxazepam and remained under the normal range during the experiment.

In order to explain the effect of propoxazepam on the body weight of the rats in this study of its toxicological effect on the food and water intake in animals were analyzed. We demonstrated that rats administered $0.9,4.5$ and $9.0 \mathrm{mg} / \mathrm{kg}$ propoxazepam does have a selectively increase in food consumption and water intake compared to control.

The preclinical results strongly suggest that benzodiazepines have a relatively direct effect to stimulate appetite. The most recent evidence suggests a mechanism by which benzodiazepines affect appetite. Benzodiazepines have not been reported to cause body weight changes in humans, although benzodiazepines induce feeding and an increase of body weight in rats (Naruse 1994). This hyperphagic effect did not escape the attention of the investigators of chlordiazepoxide, the first benzodiazepine to be the subject of research (Randall 1960). Later the hyperphagic effect has been described not only for small laboratory animals but also for larger domestic animals and farm animals. In addition, it is noteworthy that tolerance does not appear to develop to the hyperphagic effect of the benzodiazepines. In contrast, tolerance develops very quickly to the sedative effects of benzodiazepines.

Some of authors (Stratford 1997, Bannai 1998) have furnished experimental evidence that the GABAergic system plays a pivotal role in the regulation of feeding behavior and energy balance, mainly through the GABA-A receptor complex (GABA-RC), in different brain sites such as the brainstem, amygdala, hypothalamus, and particularly the ventro-medial hypothalamus. 
Our radioreceptor studies (Golovenko et al. 2018) demonstrated that a value of the $\mathrm{K}_{\mathrm{i}}$ by inhibition of specific binding of [ ${ }^{3} \mathrm{H}$ ] flumazenil with synaptic membranes from the rat brain by propoxazepam is, on average, $3.5 \pm 0.3 \mathrm{nM}$. As compared with the respective values for other benzodiazepine agents, it is a rather significant value. In particular, the similar indices for diazepam, chlordiazepoxide, nitrazepam, and oxazepam are 6.3, 220,6.4, and 14.0, respectively (Kemp 1987). Estimation of the integral activity of the compound is a rather important moment in our study. This index can be estimated according to the value of a GABA shift in the graph of displacement of the radioligand by the examined ligand in the absence and presence of $10^{-4} \mathrm{M}$ GABA. The respective calculations showed that the GABA shift for propoxazepam is equal to 1.9. This fact allows us to consider the examined compound as a full agonist of GABA RC.

Organ weight analysis is an important endpoint for identification of potentially harmful effects of test compounds in toxicology studies. One of the major objectives of any preclinical toxicity study is to identify target organs which help the clinicians to monitor related adverse effects during clinical development.

Lungs, liver, kidney, spleen, brain and heart are optimally analyzed using organ-body weight ratio to evaluate the effects of a tested substance on organ weights (Bindhu 2007). Undoubtedly, there is sex biasness; better correlation was observed in males than females for these organs.

Authors (Bruce 1951) had shown that ther is a relationship between water and food consumption for rats, but our study hadn`t showed this.It seems that another factor can influence, like described by Cizek L.J. and Nocenti M. R. (Cizek 1965). These results suggest that the mechanisms mediating feeding and drinking remain intact and responsive to the energy and water needs of the rat over a large part of its life-span.

\section{Conclusion}

The purpose of this study was to evaluate and assess the potential acute and subacute toxicity of orally administered propoxazepam to mice and rats by single and repeated dosing, respectively; and to provide information to assist in doses selection for future repeated-dose studies. Single oral dose of propoxazepam at the concentration of $2500 ; 3500 ; 4000 ; 4500$ and $5000 \mathrm{mg} / \mathrm{kg}$ was administered to mice and rats for 14-day acute as well as $0.9,4.5$, and $9.0 \mathrm{mg} / \mathrm{kg} /$ day 90 -day subchronic oral toxicity studies in male rats. The results revealed no mortalities or observed clinical signs of toxicity in all the rats during both investigation periods. These results indicated that the LD 50 of propoxazepam is higher than $5000 \mathrm{mg} / \mathrm{kg}$ and it therefore belongs to the category $\mathrm{V}$ of relatively non-toxic substances according to the GHS. In the acute toxicity study, no mortality, no significant change in the body weight and the relative organ weights were recorded in all treated mice and rats. Present data set revealed that there wasn't a strong correlation between body weights with food and water consumptions. The present investigation demonstrates, at least in part, the safety of propoxazepam suggesting its promising potential for pharmaceutical uses.

\section{References}

[1] Andronati, S., Semenishyna, E., Pavlovsky, V., Simonov, Y., Makan, S., Boyko, I., Burenkova, N., Gdaniec, M., Cardinael, P., Bouillon, J.P., Mazepa, A. (2010) Synthesis, structure and affinity of novel 3-alkoxy-1,2-dihydro-3H-1,4-benzodiazepin-2-ones for CNS central and peripheral benzodiazepine receptors. Eur J Med Chem 45(4): 1346-1351. https://doi.org/10.1016/j.ejmech.2009.12.027.

[2] Bannai, M., Ichikawa, M., Nishihara, M, Takahashi, M. (1998) Effect of injection of antisense oligodeoxynucleotides of GAD isozymes into rat ventromedial hypothalamus on food intake and locomotor activity. Brain Res. 784: 305-315. https://doi.org/10.1016/S0006-8993(97)01349-8.

[3] Bindhu M., Barry Y., Rani S. S., Rick P., Daniel M., Nigel R., Julie K. J., Ken S. Evaluation of OrganWeights for Rodent and Non-Rodent Toxicity Studies: A Review of Regulatory Guidelines and a Survey of Current Practices. Toxicologic Pathology, 35:742-750, 2007. https://doi.org/10.1080/01926230701595292.

[4] Bruce, H. M., Kennedy G. C. (1951) The central nervous control of food and water intake. J. Camp. Physiol. Psychol. 54: 580-584, I 96 I.

[5] Cizek LJ, Nocenti M. R. (1965) Relationship between water and food ingestion in the rat. Am J Physiol. 208:615-620. https://doi.org/10.1152/ajplegacy.1965.208.4.615.

[6] Golovenko N. Ya., Larionov V. B., Reder A. S., Valivodz I. P. (2017) An effector analysis of the interaction of propoxazepam with antagonists of GABA and glycine receptors. Neurochemical Journal 11, No. 4: 302-330. https://doi.org/10.1134/S1819712417040043.

[7] Golovenko N.Ya., Larionov V.B., Valivodz I.P. (2017) Absorption and distribution of 14C-Propoxazepam after its intragastral administration. Fiziolohichnyi zhurnal 63, No. 3: 40-48. https://doi.org/10.15407/fz63.03.040.

[8] Golovenko N.Ya., Larionov V.B., Andronati S.A., Valivodz I.P., Yurpalova T.A. (2018) Pharmacodynamic analysis of propoxazepam interaction with GABA-benzodiazepine-receptor-ionophore complex. Neurophysiology 50. 1: 2-11. https://doi.org/10.1007/s11062-018-9711-9.

[9] Golovenko N. Ya., Voloshchuk N. I., Andronati S. A., Taran I. V., Reder A. S., Pashynska O. S., Larionov V. B. (2018) Antinociception induced by a novel benzodiazepine receptor agonist and bradykinin receptor antagonist in rodent acute and chronic pain models. EJBPS 5, Issue 12: 79-88.

[10] Kemp J. A., Marshall G. R., Wong E. H., Woodruff G. N., "The affinities, potencies and efficacies of some benzodiazepine-receptor agonists, antagonists and inverse-agonists at rat hippocampal GABAA- receptors”, Br. J. Pharmacol., 91, No. 13, 601-608. (1987). https://doi.org/10.1111/j.1476-5381.1987.tb11253.x.

[11] Koella W.P. (1985) Animal Experimental Methods in the Study of Antiepileptic Drugs. In: Antiepileptic drugs. Berlin, Heidelberg: Springer-Verlag: 283-340. https://doi.org/10.1007/978-3-642-69518-6_12.

[12] Larionov V.B., Reder A.S. Propoxazepam, a novel analgesic with multifunctional mechanism of action: review of preclinical data. International scientific and practical conference "Prospects for the development of medicine in EU countries and Ukraine", Wloclavek, Republic of Poland, December 21-22, 2018. P.111-115.

[13] Naruse T. (1994) Effects of repeated intravenous administration of diazepam on food intake in rats. Fundam Clin Pharmacol 8: $379-384$. https://doi.org/10.1111/j.1472-8206.1994.tb00816.x.

[14] OECD Guideline for Testing of Chemicals (TG 407). Repeated Dose 28-Day Oral Toxicity Study in Rodents. OECD/OEDC. (2008)

[15] OECD Guidelines for the Testing of Chemicals.408. Repeated Dose 90-day Oral Toxicity Study in Rodents. 2017.

[16] OECD. Harmonized integrated hazard classification system for human health and environmental effects of chemical substances. 28th Joint Meeting of the Chemicals Committee and the Working Party on Chemicals, Part 2. Paris, France, 1998.

[17] Randall, L. O., Schallek, W., Heise, G. A., Keith, E. F. and Bagdon, R. E. (1960). The psychosedative properties of methaminodiazepoxide. Journal of Pharmacology and Experimental Zherapeutics, 129: 163-171. 
[18] Robert S. Gable. (2004) Acute toxic effects of club drugs. Journal of Psychoactive Drugs 36(1): 303-313 https://doi.org/10.1080/02791072.2004.10400031.

[19] Saganuwan S. A. (2017) Toxicity studies of drugs and chemicals in animals: An overview. Bulgarian Journal of Veterinary Medicine 20, No 4: 291318. https://doi.org/10.15547/bjvm.983.

[20] Stratford, T.R., Kelley, A.E. (1997) GABA in the nucleus accumbens shell partecipates in the central regulation of feeding behavior. J. Neurosci. 17: 4434 - 4440. https://doi.org/10.1523/JNEUROSCI.17-11-04434.1997.

[21] Voloshchuk N.I., Taran I.V., Reder A.S., Golovenko M.Ya. (2018) Experimental study of ulcerogenic action of propoxazepam. Reports of Vinnytsia National Medical University 22(1): 6-9. https://doi.org/10.31393/reports-vnmedical-2018-22(1)-01. 